Direitos Humanos e Democracia - Terezinha de Jesus Souza Signorini

\title{
A RECEPÇÃO DE TRATADOS INTERNACIONAIS SOBRE DIREITOS HUMANOS NO BRASIL APÓS A EMENDA CONSTITUCIONAL N.․ 45
}

\author{
Terezinha de Jesus Souza Signorini*
}

\begin{abstract}
RESUMO
$\mathrm{O}$ artigo investiga a recepção dos tratados internacionais no sistema brasileiro de proteção aos direitos humanos no país após o acréscimo do $\S 3^{\circ}$ ao art. $5^{\circ}$ da Constituição da República, trazido com a Emenda de n. ${ }^{\circ}$ 45, do ano de 2004. Tratar-seá, primeiramente, da figura dos tratados internacionais, à qual se seguirá sucinto exame da relação entre os tratados internacionais que versam sobre direitos humanos e a Constituição de 1988 - antes e após o advento da modificação constitucional referida. O destaque de diferentes opiniões doutrinárias acerca do tema permitirá a verificação de diversos aspectos pertinentes, indo além do comentado problema de direito intertemporal. Diante de tais perplexidades, mesmo que uma leitura que privilegie os direitos humanos possa trazer respostas à questão, acredita-se que o problema demanda ação do poder constituinte derivado para efetiva pacificação da discussão.
\end{abstract}

Palavras-chave:Tratados internacionais; direitos humanos; interpretação; Emenda Constitucional n. 45/2004; art. $5^{\circ}$, § $3^{\circ}$ da Constituição Federal.

\begin{abstract}
This article investigates the reception of the international treaties in the Brazilian system of protection to the human rights after the increment of the 3rd paragraph to the 5th article of the Constitution of the Republic, brought with the 45th Amendment, of 2004. Firstly, it will be treated the illustration of the international treaties, to which a brief exam of the relationship will be followed among the international treaties that turn about human rights and the Constitution of 1988 - before and after the coming of the referred constitutional modification. The prominence of different doctrinaire opinions concerning the theme will allow the verification of several pertinent aspects, going besides of the commented problem of intertemporal right. Due to such
\end{abstract}

\footnotetext{
* Promotora de Justiça Substituta em Segundo Grau no Estado do Paraná, Especialista em Direito Tributário e Processo Tributário pela PUC-PR, Especialista em Direito Público com ênfase em Direito Administrativo pela UFPR e Mestre em Direito Socioambiental pela PUC-PR. Endereço eletrônico: tjsouza@pr.gov.br
} 


\title{
A RECEPÇÃo de Tratados INTERNACIONAIS SObRe Direitos HuMANOS NO BRASIL APÓS A EMENDA CONSTITUCIONAL N. 45
}

perplexities, even if a reading that privileges the human rights can bring answers to the subject, it is believed that the problem demands action of the flowed constituent power for effective pacification of the discussion.

\begin{abstract}
SUMÁRIO: 1 INTRODUÇÃO; 2 TRATADOS INTERNACIONAIS: CONCEITUAÇÃO E RECEPÇÃO GERAL NA ORDEM JURÍDICA BRASILEIRA; 3 TRATADOS INTERNACIONAIS SOBRE DIREITOS HUMANOS E A CONSTITUIÇÃO DE 1988; 4 EFEITOS DA EMENDA CONSTITUCIONAL N. ${ }^{\circ} 45$ SOBRE O SISTEMA BRASILEIRO DE PROTEÇÃO DOS DIREITOS HUMANOS; 5 CONSIDERAÇÕES FINAIS; 6 REFERÊNCIAS.
\end{abstract}

\section{INTRODUÇÃO}

\begin{abstract}
Direitos humanos têm faces de Jano que se voltam simultaneamente para a Moral e para o Direito. (...) Referem-se eles, como normas morais, a tudo que ostenta face humana, mas, na qualidade de normas jurídicas, protegem os indivíduos apenas à medida que pertencem a determinada comunidade jurídica. (...) Dessa maneira, subsiste uma tensão peculiar entre o sentido universal dos direitos humanos e suas condições locais de concretização: eles deveriam alcançar irrestritamente validade para todas as pessoas - porém, como atingir isso? ${ }^{1}$
\end{abstract}

O presente estudo pretende, fundamentalmente, investigar como se encontra o cenário da proteção dos direitos humanos no país no que tange à influência dos tratados internacionais sobre o assunto, diante das mudanças trazidas pela Emenda Constitucional de n. ${ }^{\circ}$ 45. A referida modificação na Carta Magna, que levou à incorporação do $\S 3^{\circ}$ a seu artigo $5^{\circ}$, teria alterado também a eficácia e aplicabilidade do $\S 2^{\circ}$ do mesmo dispositivo - o qual também dispunha sobre o mesmo tema?

${ }^{1}$ HABERMAS, J. Sobre a legitimação pelos direitos humanos. In: MOREIRA, L.; MERLE, J. (Org.). Direito e legitimidade. (Trad. Claudio Molz e Tito Lívio Cruz Romão). São Paulo: Landy, 2003. p. 72. 
Inicialmente, será efetuada uma exposição rápida acerca da figura dos tratados internacionais - sua conceituação, gênese e efeitos. Segundo a opinião de Piovesan ${ }^{2}$, essas considerações iniciais fazem-se pertinentes por contribuir, primeiramente, à análise central do nexo entre a Constituição de 1988 e os tratados internacionais sobre direitos humanos, mas principalmente pelo precioso subsídio que este exame presta ao estudo do impacto jurídico desta fonte no Direito interno do país.

Seguir-se-á, então, para o ponto que relaciona os Tratados Internacionais de Direitos Humanos e a Constituição de 1988. Vale dizer que, neste momento do trabalho, a realidade mostrada corresponderá ao período anterior a 31 de dezembro de 2004, a fim de embasar a exposição da temática central deste estudo: as modificações trazidas pela Emenda n. ${ }^{\circ} 45$ à Constituição Federal atual - tópico a ser desenvolvido por derradeiro.

Serão apresentadas perspectivas diversas acerca dos efeitos que a disposição elencada no art. $5^{\circ}, \S 3^{\circ}$, traria à temática. Seguir-se-ão, a este ponto, considerações finais sobre o exposto, as quais retomam de forma sucinta o que foi abordado e se prestam a sugerir possíveis interpretações às modificações trazidas pela Emenda Constitucional n. ${ }^{\circ} 45$ à recepção de disposições sobre direitos humanos provenientes de convenções internacionais.

\section{TRATADOS INTERNACIONAIS: CONCEITUAÇÃO E RECEPÇÃO GERAL NA ORDEM JURÍDICA BRASILEIRA}

Faz-se pertinente, inicialmente, recorrer ao pensamento de Leonardo Avelino Duarte, que nos coloca a dificuldade de se encontrar um conceito determinado do que seja "tratado internacional", uma vez que ele se apresenta de diversas formas, tanto na

\footnotetext{
${ }^{2}$ PIOVESAN, F. Direitos humanos e o direito constitucional internacional. Rio de Janeiro: Max Limonad, 2000, p. 73.
} 


\section{A RECEPÇÃo de Tratados INTERNACIONAIS SObRe Direitos HuMANOS NO BRASIL APÓS A EMENDA CONSTITUCIONAL N. 45}

doutrina quanto no texto do Direito positivo da Constituição Federal. ${ }^{3}$ A Convenção de Viena define o tratado internacional como "um acordo internacional celebrado entre Estados de forma escrita e regido pelo Direito internacional, que conste ou de um instrumento único ou de dois ou mais instrumentos conexos, qualquer que seja sua denominação específica" (art. $2^{\circ}, 1^{\circ}$, letra a).

O referido autor destaca que Francisco Rezek, por sua vez, visualiza o tratado como "todo o acordo formal concluído entre sujeitos de Direito Internacional público, e destinado a produzir efeitos jurídicos". 4

$\mathrm{Na}$ mesma esteira, o jurista Alexandre de Moraes conceitua tratado internacional como "acordo entre dois ou mais sujeitos da comunidade internacional que se destina a produzir determinados efeitos jurídicos". 5

Denota-se da construção desses conceitos pela doutrina que, inegavelmente, os tratados internacionais consistem na principal fonte de obrigação do Direito Internacional, como "acordos internacionais juridicamente obrigatórios e vinculantes". ${ }^{6}$ Podem introduzir novas regras, bem como complementar ou modificar disposições pré-existentes. Levando em consideração os tratados estabelecidos entre Estados - os quais importam a este estudo -, vale esclarecer que eles obrigam apenas aos signatários, uma vez que devem ser expressão de consenso, nunca oriundos de imposição.

De maneira geral, a negociação, conclusão e assinatura de um tratado competem a órgão do Poder Executivo. A assinatura, incluída no processo de negociação, atesta a autenticidade e a definitividade do tratado, mas não é capaz de,

${ }^{3}$ DUARTE, L. A. Estudos sobre a posição hierárquica dos decretos legislativos que incorporam tratados. Revista de Direito Constitucional e Internacional, São Paulo, a. 10, n. 41, p. 74, out./dez 2002.

${ }^{4}$ Apud, ibidem, p. 73.

${ }^{5}$ MORAES, A. de. Direitos humanos fundamentais: teoria geral, comentários aos arts. $1^{\circ}$ a $5^{\circ}$ da Constituição da República Federativa do Brasil, doutrina e jurisprudência. São Paulo: Atlas, 1998, p. 299.

\footnotetext{
${ }^{6}$ PIOVESAN, op. cit., p. 73.
} 
por si só, gerar obrigações: há a necessidade do desempenho de outros atos, conforme se explicitará a seguir. ${ }^{7}$

A devida incorporação de ato ou tratado internacional ao ordenamento jurídico brasileiro compreende três etapas distintas. A primeira compete privativamente ao Presidente da República, de acordo com o art. 84, inc. VIII, da CF.

A seguinte, por sua vez, cabe exclusivamente ao Congresso Nacional: consiste em examinar e expedir a resolução definitiva sobre estes tratados, acordos ou atos internacionais que impliquem encargos gravosos ao patrimônio nacional - conforme disposto do art. 49, inc. I, da CF. Tal deliberação é realizada por meio da aprovação de um decreto legislativo - o qual deverá ser promulgado pelo Presidente da República e publicado.

A última fase consiste na edição de um decreto presidencial, o qual é apto a promulgar o ato ou tratado internacional já devidamente ratificado pelo Congresso Nacional. Somente nesta etapa a norma inserida pelo ato ou tratado internacional adquire executoriedade. ${ }^{8}$

Tal sistemática seria expressão genuína do Constitucionalismo e do sistema de pesos e contrapesos, pois ao "atribuir o poder de celebrar tratados ao Presidente, mas apenas mediante referendo do Legislativo, busca-se limitar e descentralizar o poder de celebrar tratados, prevenindo o abuso desse poder". 9

Alexandre de Moraes considera que as normas previstas em atos ou tratados internacionais, mediante aprovação pelo Poder Legislativo e promulgação pelo Presidente da República, ingressariam como atos normativos infraconstitucionais na ordem jurídica brasileira - ou seja, com valor hierárquico de leis ordinárias. Portanto, quaisquer conflitos entre normas ordinárias de direito interno e as decorrentes de atos ou tratados internacionais seriam solucionados por meio da utilização do critério

\footnotetext{
${ }^{7}$ Ibidem, p. 77.

${ }^{8}$ MORAES, op. cit., p. 299.

${ }^{9}$ Apud PIOVESAN, op. cit., p. 80.
} 


\section{A RECEPÇÃo de Tratados InTERnACIONAIS SObRe Direitos HuMANOS NO BRASIL APÓS A EMENDA CONSTITUCIONAL N. 45}

cronológico ou do princípio da especialidade. Defende, portanto, a supremacia das normas constitucionais em relação aos tratados e atos internacionais - ainda que devidamente ratificados -, bem como a suscetibilidade de tais normas ao controle de constitucionalidade. ${ }^{10}$

Canotilho e Moreira, segundo a leitura de Alexandre de Moraes, teriam entendimento semelhante - conforme comprova a seguinte transcrição de texto daqueles: "(...) as normas de direito internacional público vigoram na ordem interna com a mesma relevância das normas de direito interno, desde logo quanto à subordinação da Constituição - sendo, pois, inconstitucionais se infringirem as normas da Constituição ou os seus princípios". ${ }^{11}$

Para esses autores significa, portanto, que tais atos normativos não guardariam nenhuma validade ao afrontar preceito da Constituição Federal, pois perderiam eficácia ao se submeterem ao controle difuso ou concentrado de constitucionalidade.

\section{TRATADOS INTERNACIONAIS SOBRE DIREITOS HUMANOS E A CONSTITUIÇÃO DE 1988}

Mesmo em relação aos tratados ou atos internacionais cujo conteúdo corresponda à matéria de direitos humanos, Alexandre de Moraes, antes da entrada em vigor da Emenda Constitucional $\mathrm{n}^{\mathrm{o}}$ 45, colocava-os em posição de infraconstitucionalidade. Para reforçar seu entendimento, cita a posição de Manoel Gonçalves Ferreira Filho, que defende a existência de dois patamares de direitos fundamentais da ordem jurídica brasileira: "um constitucional, outro meramente legal". 12

\footnotetext{
${ }^{10}$ MORAES, op. cit., p. 300.

${ }^{11}$ Apud, ibidem, p. 301.

${ }^{12}$ FERREIRA FILHO, M. G. Direitos Humanos Fundamentais. São Paulo: Saraiva, 1995, p.
} 
Também faz menção, como exemplo de consagração da supremacia constitucional, à decisão do Supremo Tribunal Federal pela manutenção das hipóteses de prisões civis de inadimplemento voluntário, depositário infiel e inescusável de obrigação alimentar - afirmação da vigência e eficácia do art. $5^{\circ}$, inc. LXVII, perante o art. $7^{\circ}$, n. ${ }^{\circ}$, do Pacto de São José da Costa Rica (tratado ratificado por Decreto legislativo em 1992, e posteriormente promulgado e publicado pelo Presidente da República). ${ }^{13}$

Luiz Ximenes ROCHA, por seu turno, coaduna-se a entendimento diverso, ao acreditar que os tratados internacionais que versam sobre direitos humanos possuem status normativo constitucional - antes mesmo da promulgação da Emenda n. ${ }^{\circ} 45$. Seu pensamento resta explícito nas seguintes considerações:

Posição feliz do nosso constituinte de 1988, ao consagrar que os direitos garantidos nos tratados de direitos humanos em que a República Federativa do Brasil é parte recebem tratamento especial, inserindo-se no elenco dos direitos constitucionais fundamentais, tendo aplicação imediata no âmbito interno, a teor do disposto nos $\S \S 1^{\circ}$ e $2^{\circ}$ do art. $5^{\circ}$ da Constituição Federal. ${ }^{14}$

Já PASSOS partilha da opinião de que os direitos humanos estariam inseridos em uma posição supraconstitucional, "pairando por sobre todos os outros direitos e garantias fundamentais, os quais só têm sentido após serem devidamente tutelados os mencionados direitos humanos de que aqueles não podem prescindir". ${ }^{15}$ Além disso, para o autor, os parágrafos $1^{\circ}$ e $2^{\circ}$ do art. $5^{\circ}$ da $\mathrm{CF}$ explicitariam nitidamente a aplicabilidade imediata dos direitos e garantias fundamentais, a incluir os direitos humanos decorrentes de tratados e convenções internacionais de que o país é parte.

99. Apud: MORAES, op. cit., p. 302.

${ }^{13}$ Ibidem, loc. cit.

${ }^{14}$ ROCHA, L. X. A incorporação dos tratados e convenções internacionais de direitos humanos no direito brasileiro. Revista de informação legislativa, n. 130, p. 81. Apud: Ibidem, p. 302.

${ }^{15}$ PASSOS, J. L. T. C. de. Direitos humanos na reforma do judiciário. In: WAMBIER, Teresa Arruda Alvim (org.). Reforma do Judiciário: primeiros ensaios críticos sobre a EC n. 45/2004. São Paulo: Revista dos Tribunais, 2005. p. 351. 


\section{A RECEPÇÃo de Tratados InTERnACIONAIS SObRe Direitos HuMANOS NO BRASIL APÓS A EMENDA CONSTITUCIONAL N. 45}

Transcrevem-se, abaixo, os dispositivos referidos para melhor demonstração do raciocínio exposto:

Art. $5^{\circ}$.

(...)

$\S 1^{\circ}$ - As normas definidoras dos direitos e garantias fundamentais têm aplicação imediata.

$\S 2^{\circ}$ - Os direitos e garantias expressos nesta Constituição não excluem outros decorrentes do regime e dos princípios por ela adotados, ou dos tratados internacionais em que a República Federativa do Brasil seja parte.

Segundo essa linha de pensamento, os tratados internacionais em geral gozariam de hierarquia infraconstitucional, conforme o disposto pelo art. 102, inc. III, alínea $b$, da $\mathrm{CF}$ - mas isto não se aplica aos tratados que protegem direitos humanos, dada sua fundamentalidade para o ordenamento jurídico.

O autor respalda-se em Celso de Albuquerque Mello para defender sua opinião, já que também este jurista defende que a norma internacional prevaleceria sobre a norma constitucional nesta matéria. Cita ainda a opinião de Antonio Augusto Cançado Trindade - o qual considera que os tratados de proteção internacional dos direitos humanos integram o elenco dos direitos constitucionalmente consagrados, mas considera desnecessária a intermediação do Poder Legislativo para que sejam eficazes e aplicáveis. ${ }^{16}$

O Supremo Tribunal Federal, contudo, vem adotando a posição de que os tratados internacionais, mesmo quando abordam matéria relativa a direitos humanos, seriam incorporados ao Direito brasileiro como norma ordinária. Neste sentido, segue abaixo a decisão da Suprema Corte:

Prevalência da Constituição, no Direito brasileiro, sobre quaisquer convenções internacionais, incluídas as de proteção aos direitos humanos, que impede, no caso, a pretendida aplicação da norma do Pacto de São José: motivação. A Constituição do Brasil e

${ }^{16}$ Ibidem, p. 353. 
Revista Eletrônica do CEJUR, Curitiba-PR, a. 2, v. 1, n. 3, ago./dez. 2008

as convenções internacionais de proteção aos direitos humanos: prevalência da Constituição que afasta a aplicabilidade das cláusulas convencionais antinômicas. (...) Assim como não o afirma em relação às leis, a Constituição não precisou dizer-se sobreposta aos tratados: a hierarquia está ínsita em preceitos inequívocos seus, como os que submetem a aprovação e a promulgação das convenções ao processo legislativo ditado pela Constituição e menos exigente que o das emendas a ela e aquele que, em consequiência, explicitamente admite o controle da constitucionalidade dos tratados (CF, art. 102, III, ). Alinhar-se ao consenso em torno da estatura infraconstitucional, na ordem positiva brasileira, dos tratados a ela incorporados, não implica assumir compromisso de logo com o entendimento majoritário em recente decisão do STF (ADI 1.480-MC) que, mesmo em relação às convenções internacionais de proteção de direitos fundamentais, preserva a jurisprudência que a todos equipara hierarquicamente às leis ordinárias. Em relação ao ordenamento pátrio, de qualquer sorte, para dar a eficácia pretendida à cláusula do Pacto de São José, de garantia do duplo grau de jurisdição, não bastaria sequer lhe conceder o poder de aditar a Constituição, acrescentando-lhe limitação oponível à lei como é a tendência do relator: mais que isso, seria necessário emprestar à norma convencional força ab-rogante da Constituição mesma, quando não dinamitadoras do seu sistema, o que não é de admitir. (BRASIL. Supremo Tribunal Federal, RHC 79.785, Rel. Min. Sepúlveda Pertence, DJ 22/11/02).

Flávia Piovesan pondera, contudo, que os direitos garantidos nos tratados de direitos humanos dos quais o país é signatário integram o conjunto de direitos constitucionalmente consagrado. Tal conclusão seria fundamentada, primeiramente, pela efetuação de uma "interpretação sistemática e teleológica do texto, especialmente em face da força expansiva dos valores da dignidade humana e dos direitos fundamentais, como parâmetros axiológicos a orientar a compreensão do fenômeno constitucional". ${ }^{17}$

Em segundo lugar, isso se deveria à natureza constitucional de cunho material dos direitos fundamentais - algo tornado claro pela previsão do $\S 2^{\circ}$, do art. $5^{\circ}$ de nossa Carta Constitucional: verdadeira cláusula de abertura à complementação do elenco de direitos fundamentais positivados no texto constitucional, dando espaço à idéia de "bloco de constitucionalidade". A professora propõe uma classificação original dos direitos previstos pela Constituição: a) expressos; b) expressos em tratados internacionais de que o país seja parte; c) implícitos. ${ }^{18}$

O princípio da máxima efetividade das normas constitucionais também

\footnotetext{
${ }^{17}$ PIOVESAN, F. Op. cit., p. 83.

${ }^{18}$ Ibidem, p. 89.
} 


\section{A RECEPÇÃo de Tratados INTERNACIONAIS SOBRE DireITOS HUMANOS NO BRASIL APÓS A EMENDA CONSTITUCIONAL N. 45}

embasaria a idéia de que as regras decorrentes de tratados internacionais sobre direitos humanos, nos quais o Brasil figure como parte, sejam de status constitucional, já que no âmbito dos direitos fundamentais isso se faria essencial. Também a noção de jus cogens reforçaria a idéia: "os tratados de direitos apresentariam superioridade hierárquica relativamente aos demais atos internacionais de caráter mais técnico, formando um universo de princípios que apresentam força especial obrigatória". ${ }^{19}$

Piovesan ainda ressalta o quão notável é o texto disposto no art. $5^{\circ}, \S^{\circ}$ de nossa Constituição, ao estabelecer a aplicabilidade imediata dos direitos e garantias fundamentais - a qual caberia às normas de tratados internacionais de direitos humanos, uma vez que estes visam à definição de direitos e garantias. Os efeitos decorrentes da previsão do $\S 1^{\circ}$, portanto, seriam a possibilidade de invocação direta dos direitos e liberdades assegurados internacionalmente e a perda automática da vigência de qualquer norma que contrarie tratado deste gênero. Haveria também aqui a afirmação da concepção monista - a qual defende que Direito Internacional e Direito Interno formam uma unidade - ao contrário da dualista, que acredita que esses dois ramos são incomunicáveis. ${ }^{20}$

A autora defende, contudo, a infraconstitucionalidade e inaplicabilidade automática dos demais tratados - que não versem sobre direitos humanos -, remetendo ao art. 102, inc. III, alínea $b$, o qual acredita que posiciona os demais tratados e as leis federais no mesmo grau hierárquico. Destaca-se esse texto legal abaixo:

Art. 102

(...)

III- julgar, mediante recurso extraordinário, as causas decididas em única ou última instância, quando a decisão recorrida:

(...)

b) declarar a inconstitucionalidade de tratado ou lei federal;

\footnotetext{
${ }^{19}$ Ibidem, p. 96.

${ }^{20}$ PIOVESAN, F. Op. cit., p. 103-104.
} 
Acerca da efetivação do sistema brasileiro de incorporação automática e em paridade constitucional dos tratados de direitos humanos de que o país seja signatário, Piovesan afirma que:

Em síntese, o Direito Internacional dos Direitos Humanos pode reforçar a imperatividade de direitos constitucionalmente garantidos - quando os instrumentos internacionais complementam dispositivos nacionais, ou quando estes reproduzem preceitos enunciados da ordem internacional - ou ainda estender o elenco dos direitos constitucionalmente garantidos - quando os instrumentos internacionais adicionam direitos não previstos pela ordem jurídica interna. $^{21}$

E acerca de possíveis conflitos entre o Direito interno e o Direito Internacional dos Direitos Humanos? O critério a ser seguido seria o da "escolha da norma mais favorável à vítima"22, já que a primazia é pela pessoa humana.

\section{EFEITOS DA EMENDA CONSTITUCIONAL N..$^{\circ} 45$ SOBRE O SISTEMA BRASILEIRO DE PROTEÇÃO DOS DIREITOS HUMANOS}

O texto transcrito abaixo se refere à temática central do trabalho: a alteração da Constituição trazida pela Emenda Constitucional $n^{\circ} 45$, no que tange aos Tratados Internacionais de direitos humanos. Essa disposição normativa estabelece que, para que tais regras dessa origem tenham eficácia e aplicabilidade, elas necessitam de aprovação, em cada Casa do Congresso Nacional, em dois turnos, por três quintos dos votos dos respectivos membros.

Art. $5^{\circ}$.

(...)

\footnotetext{
${ }^{21}$ Ibidem, p. 121.

${ }^{22}$ Idem.
} 


\section{A RECEPÇÃo de Tratados INTERNACIONAIS SOBRE Direitos HUMANOS NO BRASIL APÓS A EMENDA CONSTITUCIONAL N. 45}

$\S 3^{\circ}$ : Os tratados e convenções internacionais sobre direitos humanos que forem aprovados, em cada Casa do Congresso Nacional, em dois turnos, por três quintos dos votos dos respectivos membros, serão equivalentes às emendas constitucionais.

Tal texto, para alguns estudiosos, ${ }^{23}$ teria denotado a intenção de equiparar normas acerca de direitos humanos provenientes de tratados internacionais a emendas constitucionais, já que repetiria o quorum para aprovação de Emenda à Constituição, previsto no $\S 2^{\circ}$, do art. 60 da Lex Mater em vigor:

Art. 60. A Constituição poderá ser emendada mediante proposta:

(...)

$\S 2^{\circ}$ - A proposta será discutida e votada em cada Casa do Congresso Nacional, em dois turnos, considerando-se aprovada se obtiver, em ambos, três quintos dos votos dos respectivos membros.

Roberto Luchezi considera que tal disposição confrontaria o entendimento da teoria monista - ou seja, que bastaria a simples adesão ao tratado sobre direitos humanos, para que o mesmo fosse, automaticamente, incorporado ao ordenamento jurídico pátrio, sem mesmo a necessidade de sua ratificação pelo Congresso e pelo Executivo. O jurista ainda lembra que o Brasil já vinha seguindo a prática de incorporação por meio de procedimento legislativo, mencionando como exemplos, a Convenção Americana sobre Direitos Humanos (Convención Americana Sobre Derechos Humanos, também designada Pacto de San José da Costa Rica) e o Pacto Internacional de Direitos Civis e Políticos, que foram incorporados ao nosso ordenamento jurídico por meio dos Decretos Legislativos $n^{\circ} \mathrm{s} .27$, de 25 de setembro de 1992, e 226, de 12 de dezembro de 1991 e Decretos Presidenciais nº ${ }^{\circ}$. 678, de 6 de novembro de 1992, e 592, de 6 de julho de 1992, respectivamente.

Muitos estudiosos acreditam que haveria coexistência de duas possibilidades

${ }^{23}$ LUCHEZI, R. A Emenda Constitucional no 45 . Jus Navigandi, Teresina, a. 9, n. 560, 18 jan. 2005. Disponível em: <http://jus2.uol.com.br/doutrina/texto.asp?id=6176>. Acesso em: 31 ago. 2005. 
de recepção dos tratados: poderiam ser recebidos como leis ordinárias - entendimento muitas vezes assumido pelo Pretório Excelso, no qual a recepção era dada via decreto legislativo (à maneira dos tratados em geral) - ou como leis constitucionais - sendo que, para que alcancem esse último patamar, devem obedecer o procedimento estabelecido pelo art. $5^{\circ}, \S 3^{\circ}, \mathrm{CF}$.

Tal posição é defendida por Antonio Henrique Lindemberg BALTAZAR, que afirma que "a opção de incorporação de tratados e convenções internacionais sobre direitos humanos com o status de lei ordinária (regra geral) ou com o status de norma constitucional $\left(\mathrm{CF}\right.$, art. 5, $\left.\S 3^{\circ}\right)$ é ato discricionário do Congresso Nacional e dependerá de seu julgamento de oportunidade e conveniência quando da análise do caso concreto". ${ }^{24}$

Assim também entende o professor mineiro José Levi Mello do Amaral Júnior, o qual acredita que o maior mérito da inovação trazida pela Emenda Constitucional foi o sepultamento da polêmica acerca do status constitucional das normas de tratados internacionais de direitos humanos, uma vez que "no modelo constitucional originário de 1988, nada impedia que o conteúdo de um tratado ou convenção internacional fosse posto em uma proposta de emenda constitucional - a ser deliberada nos termos do art. 60 da Constituição de 1988 - e viesse a vigorar, por exemplo, como uma lei constitucional autônoma". ${ }^{25}$

Em resposta ao posicionamento deste autor, no mesmo periódico eletrônico, em data posterior, o advogado Aldo de Campos Costa contrapôs que a emenda, "além de não ter eliminado a polêmica doutrinária e jurisprudencial concernente à hierarquia dos tratados internacionais de proteção dos direitos humanos, apenas serviu para trazer

\footnotetext{
${ }^{24}$ BALTAZAR, A. H. L. Aulas, artigos e entrevistas, 19 de julho de 2005. Disponível em:
} $<$ http://www.vemconcursos.com.br/opiniao/index.phtml?page_sub=5\&page_id=1818>. Acesso em 31 ago. 2005.

25 AMARAL JÚNIOR, J. L. M. do. Reforma define o status jurídico de tratados internacionais. Consultor Jurídico. Direitos humanos, 26 de janeiro de 2005. Disponível em: <http://conjur.estadao.com.br/static/text/32678,1>. Acesso em 31 ago 2005. 


\section{A RECEPÇÃo de Tratados INTERNACIONAIS SObRe Direitos HuMANOS NO BRASIL APÓS A EMENDA CONSTITUCIONAL N. 45}

mais confusão à exegese da matéria". ${ }^{26}$ Teria andado mal o legislador reformador ao não deixar explícita a atribuição do mesmo regime jurídico aos tratados internacionais sobre direitos humanos já ratificados pelo Brasil.

Tal anacronismo teria sido observado pelo Conselho de Defesa dos Direitos da Pessoa Humana, o qual examinou as alterações propostas pela PEC 29/2000, acerca da Reforma do Judiciário, no tocante à inclusão do dispositivo ao artigo $5^{\circ}$ da Constituição Federal. Tal Conselho sugeriu, na época, que a redação do dispositivo afirmasse que "os tratados internacionais de proteção de direitos humanos ratificados pelo Estado brasileiro têm hierarquia constitucional"; ou, alternativamente, que a redação fosse reformulada para "os tratados internacionais de proteção dos direitos humanos aprovados, em cada Casa do Congresso Nacional, em dois turnos, por três quintos dos votos dos respectivos membros, gozarão de hierarquia constitucional". ${ }^{27} \mathrm{~A}$ não aceitação dessas sugestões levou ao presente dilema: como conferir o mesmo regime jurídico dos tratados internacionais de direitos humanos que venham a ser ratificados pelo país àqueles já ratificados?

Há ainda quem veja no novo texto constitucional a corroboração do que afirma o $\S 2^{\circ}$ do art. $5^{\circ}$, como o autor Ferrari Neto, que diz o seguinte:

Com a entrada em vigor desta Emenda acabou a polêmica sobre a hierarquia dos tratados internacionais sobre direitos humanos em face da Constituição, posto que a partir desta, todos os tratados aprovados pelo Congresso Nacional por três quintos dos membros de cada uma das casas legislativas, em dois turnos de votação, serão equivalentes às emendas constitucionais, conforme anteriormente defendido pela prof ${ }^{a}$. Flávia Piovesan, ou seja, terão eficácia de norma constitucional, e de acordo com o $\S 1^{\circ}$ da Constituição Federal, terão aplicação imediata, não dependendo de nenhuma outra lei ou decreto para entrar em vigor ou ter validade. ${ }^{28}$

${ }^{26}$ COSTA, A. de C. Reforma gera tumulto em tratados internacionais. Consultor Jurídico. Direitos humanos, 31 de janeiro de 2005. Disponível em: <http://conjur.estadao.com.br/static/text/32678,1>. Acesso em 31 ago 2005.

${ }^{27}$ Idem.

${ }^{28}$ FERRARI NETO, L. A. Estudo comparado sobre a Emenda Constitucional no 45/2004. Jus Navigandi, Teresina, a. 9, n. 670, 6 maio 2005. Disponível em: <http://jus2.uol.com.br/doutrina/texto.asp?id=6681>. Acesso em: 31 ago. 2005. 
Contudo, na opinião de Ferreira e Tárrega, ${ }^{29}$ a polêmica existente acerca do status dos tratados internacionais não teria sido resolvida com a Emenda, uma vez que ela padeceria de inconstitucionalidade. Os autores alegam, já de início, que ela contrariaria o Pacto de San José da Costa Rica, do qual o Brasil é signatário, o qual estabelece que:

(...) nenhuma disposição da presente convenção pode ser interpretada no sentido de: a) permitir a qualquer dos Estados-Partes, grupo ou indivíduo, suprimir o gozo e o exercício dos direitos e liberdades reconhecidos na Convenção, ou limitá-los em maior medida do que nela prevista; b) limitar o gozo e o exercício de qualquer direito ou liberdade que possam ser reconhecidos em virtude de leis de qualquer dos Estados-Partes (...).

Os autores ainda ressaltam certos aspectos específicos do texto da Emenda, dentre os quais o estabelecimento de um quorum qualificado para a aprovação destes tratados. Acreditam que tal medida cria um sério problema de direito intertemporal, ao deixar indefinido o vasto campo dos tratados dos quais o Brasil tornou-se parte antes de 31 de dezembro de 2004. O que aconteceria com os tratados anteriores acerca de direitos humanos que não passaram por este procedimento indicado? Ferreira e Tárrega obtemperam que "certamente, vozes retrógradas se levantarão para sustentar que eles não podem ter força constitucional, uma vez que não se submeteram ao quorum exigido pela emenda". ${ }^{30}$ Ressaltam, contudo, que também não haveria previsão em nosso texto positivo que impusesse a necessidade de que um tratado em vigor tivesse de ser submetido novamente a votação no Congresso Nacional apenas para aumento de quorum.

A lógica pretendida seria adequada: se o quorum para mudança de norma constitucional é de três quintos dos votos das duas casas em dois turnos de votação, o ingresso de uma norma de status constitucional - como muitos julgam ser o de um

${ }^{29}$ FERREIRA, L. A. C.; TÁRREGA, M. C. V. B. Reforma do poder judiciário e direitos humanos. In: WAMBIER, T. A. A. (Org.). Reforma do judiciário: primeiros ensaios críticos sobre a EC n. 45/2004. São Paulo: Revista dos Tribunais, 2005. p. 456.

${ }^{30}$ Idem. 


\section{A RECEPÇÃo de Tratados INTERNACIONAIS SOBRE DirEITOS HUMANOS NO BRASIL APÓS A EMENDA CONSTITUCIONAL N. 45}

tratado de direitos humanos - deveria passar pelo mesmo procedimento. No entanto, a exigência de tal processo deveria ter sido uma exigência do constituinte originário - o qual, contudo, optou por abrir mão de quaisquer formalidades para acolher a proteção de direitos humanos proveniente de tratado internacional. Nesse sentido, Ferreira e Tárrega afirmam que o poder reformador teria ultrapassado seus limites, já que os direitos humanos inserir-se-iam no núcleo imutável estabelecido pelo constituinte de 1988: os direitos humanos seriam cláusulas pétreas, não podendo assim sofrer modificações provenientes de emenda, conforme disposto no art. $60, \S 4^{\circ}$, inc. IV, verbis:

Art. 60

(...)

$\S 4^{\text {o: }}$ Não será objeto de deliberação a proposta de emenda tendente a abolir:

(...)

IV - os direitos e garantias individuais.

Da mesma forma entende Jorge Calmon de Passos, com apoio nas palavras de Ives Gandra Martins, para reforçar seu pensamento. Martins diz que "os direitos e garantias individuais conformam uma norma pétrea. Não são eles apenas os que estão no art. $5^{\circ}$, mas, como determina o $\$ 2^{\circ}$ do mesmo artigo, incluem outros que se espalham pelo texto Constitucional e outros que decorrem da implicitude inequívoca". ${ }^{31}$

Passos também considera inconstitucional o $\$ 3^{\circ}$ do art. $5^{\circ}$ da $C F$. Primeiramente, pelo motivo já exposto: ele defende que a adição desse parágrafo representou um atentado contra cláusulas pétreas (art. 60, IV, §4º $)$ O autor alega ainda que esse dispositivo representa uma verdadeira afronta ao princípio da prevalência dos

${ }^{31}$ MARTINS, I. Gandra. Comentários à Constituição do Brasil: promulgada em 5 de outubro de 1988. São Paulo: Saraiva, 1995, p. 371. Apud: PASSOS, J. L. T. C. de. Direitos humanos na reforma do judiciário. In: WAMBIER, T. A. A. (Org.). Reforma do Judiciário: primeiros ensaios críticos sobre a EC n. 45/2004. São Paulo: Revista dos Tribunais, 2005. p. 351. 
direitos humanos nas relações internacionais, caríssimo ao país, disposto do art. $4^{\circ}$, inc. II, verbis:

Art. 4: A República Federativa do Brasil rege-se nas suas relações internacionais pelos seguintes princípios:

(...)

II - prevalência dos direitos humanos;

A própria magnitude supraconstitucional com a qual o jurista qualifica os direitos humanos seria ofendida com a disposição trazida pela Emenda n. ${ }^{\circ} 45 .^{32}$

Em contrapartida, Ingo Sarlet não acredita que o $\$ 3^{\circ}$ seja necessariamente inconstitucional, uma vez que sua harmonização às demais regras constitucionais exigiria apenas um esforço hermenêutico construtivo. Defende, assim, a verificação da primazia da norma mais favorável no caso concreto, uma vez que não se poderia determinar a priori quais situações desrespeitariam a dignidade humana. Faz remissão à prisão civil para demonstrar seu raciocínio, pois ainda que a restrição de liberdade possa representar a violação da dignidade da pessoa humana, esta também pode restar fundamentalmente atingida quando o alimentando não percebe as prestações de que necessita para viver. ${ }^{33}$

Clémerson Merlin Cléve, em palestra proferida na Universidade Federal do Paraná $^{34}$, defendeu que a iniciativa acaba por representar um verdadeiro retrocesso, preponderantemente pela criação de um problema grave da ordem de direito intertemporal - coadunando-se à posição de outros estudiosos citados neste trabalho.

${ }^{32}$ PASSOS, J. L. T. C. de. Op. cit., p. 353.

${ }^{33}$ SARLET, I. W. Hierarquia normativa e conflitos de direitos no plano das relações entre tratados e constituição. Exposição apresentada no Painel Regime constitucional de incorporação dos tratados internacionais sobre direitos humanos, em 13 de novembro de 2006, no IX Congresso IberoAmericano e VII Simpósio Nacional de Direito Constitucional, ocorrido no Estação Embratel Convention Center, Curitiba-PR.

${ }^{34}$ CLÉVE, C. M. Reforma do Judiciário. Palestra proferida em 02 de setembro de 2005, na Universidade Federal do Paraná. 


\section{A RECEPÇÃO DE TRATADOS INTERNACIONAIS SOBRE DIREITOS HUMANOS NO BRASIL APÓS A EMENDA CONSTITUCIONAL N. 45}

A esse respeito, o autor aprestou o seguinte questionamento: seria razoável submeter todos os tratados internacionais já incorporados - e não constitucionalizados, conforme deixaria implícita a nova norma - ao procedimento requerido pelo $\S 3^{\circ}$ do art. $5^{\circ}$ da CF?

Nesse sentido, faz-se pertinente mencionar o entendimento do Ministro aposentado do Supremo Tribunal Federal, Carlos Mário da Silva Velloso, que acredita que os tratados internacionais sobre direitos humanos que tenham sido recepcionados no país antes da vigência da Emenda n. ${ }^{\circ}$ 45/2004 devem ser compreendidos como "normas com blindagem constitucional". Defende, portanto, que somente os tratados posteriores ao advento da Emenda mencionada têm de passar pelo procedimento previsto no $\S^{\circ}$ do art. $5^{\circ}$ para que tenham feição constitucional..$^{35}$

Coaduna-se a esse entendimento Paulo Ricardo Schier, ao lembrar que essa interpretação consiste na aplicação do princípio tempus regit actum, amplamente aceito pelo próprio STF em diversas situações. ${ }^{36}$ Acrescenta, ainda, que essa interpretação "otimista" do $\S 3^{\circ}$, do art. $5^{\circ}$, da $\mathrm{CF}$, antes de sepultar as teses progressistas do bloco de constitucionalidade, possibilita a confirmação da hierarquia

${ }^{35}$ VELLOSO, C. M. da S. Bioética, engenharia genética e direitos humanos: mecanismos constitucionais de proteção dos direitos humanos. Conferência proferida em 12 de novembro de 2006, no IX Congresso Ibero-Americano e VII Simpósio Nacional de Direito Constitucional, ocorrido no Estação Embratel Convention Center, Curitiba-PR.

${ }^{36}$ SCHIER faz remissão à seguinte situação de direito infraconstitucional: "Como se referiu, este entendimento já foi, anteriormente, utilizado para resolver o debate sobre as normas gerais de direito tributário disciplinadas no Código Tributário Nacional, veiculado, em 1966, como lei ordinária, em plena consonância com a Constituição de 1946. Após, com advento da Constituição de 1967, definiu-se que apenas lei complementar poderia definir tais normas gerais. Debateu-se, então, se as normas gerais do CTN foram recepcionadas ou não pela nova ordem constitucional. O Supremo Tribunal Federal, reiteradas vezes, aplicou o tempus regit actum para afirmar que, observado o procedimento sob o qual foram editadas, as normas gerais de Direito Tributário seriam recepcionadas com status e hierarquia de Lei Complementar. Paradigmática, aqui, por exemplo, a decisão proferida no Recurso Extraordinário n. ${ }^{\circ}$ 79.212, oriundo de São Paulo, julgado em 1975, com célebre discussão entre os Ministros Aliomar Baleeiro e Leitão de Abreu. Na década de 80, foi a vez do Ministro Moreira Alves, no julgamento do Recurso Extraordinário n. ${ }^{\circ}$ 93.850, reiterar este entendimento do STF". In: SCHIER, P. R. Hierarquia Constitucional dos Tratados Internacionais de Direitos Humanos e EC 45 - tese em favor da incidência do tempus regit actum. Anais do XIV Congresso Nacional do CONPEDI - Fortaleza, de 3-5 de novembro de 2005. Disponível em: $<$ http://www.conpedi.org/manaus/arquivos/Anais/Paulo\%20Ricardo\%20Schier.pdf>. Acesso em 29 fev. 2008. 
constitucional.

André Luiz Junqueira, por seu turno, posiciona-se como favorável ao privilégio da proteção dos direitos humanos, conforme fica explícito no seguinte excerto:

\begin{abstract}
Nossa interpretação tem como base a atual política brasileira, que é a de reafirmar sua posição em defesa dos direitos humanos. Ora, se este foi o objetivo dos criadores da emenda, não podemos, em nossa opinião, interpretar o texto a contrario sensu como limitador dos direitos humanos. Ademais, a criação do $\S 2^{\circ}$ do artigo $5^{\circ}$ em 1988 já fora alvo de críticas pelos estudiosos, pois a sua mera presença seria um obstáculo para acordos internacionais. A criação de ambos os dispositivos, ao nosso ver, declara a preocupação do Congresso Nacional de constitucionalizar o Direito Internacional, mas compreendemos que o detalhismo característico de nossa Carta Constitucional é realmente fomentador de discussões e que o melhor seria uma norma mais ampla conferindo aos acordos internacionais a mesma importância da Constituição. ${ }^{37}$
\end{abstract}

Já Luís Fernando Sgarbossa acredita que tal inclusão sequer deveria ter prosseguido como proposta no processo legislativo correspondente, dada a frustração gerada no intento do legislador constitucional originário - qual seja, a de assegurar a inclusão automática de tais direitos.

Além disso, o jurista afirma que, como os parágrafos $1^{\circ}$ e $2^{\circ}$ do art. $5^{\circ}$ da Constituição de 1988 constituiriam, de per se, garantias fundamentais, ao estabelecer a imediata aplicabilidade das normas definidoras de direitos e garantias fundamentais e a inclusão automática dos direitos e garantias fundamentais consagrados em instrumentos internacionais, tal emenda tenderia à abolição de direitos e garantias fundamentais. Isso não decorreria unicamente por meio de supressão literal, mas também pela criação de óbices ao exercício de direitos, "ainda que por meio de jogo de palavras, como no caso presente". ${ }^{38}$

37 JUNQUEIRA, A. L. Implicações da Emenda Constitucional n ${ }^{\mathbf{o}}$ 45/2004 no Direito Internacional. Jus Navigandi, Teresina, a. 9, n. 614, 14 mar. 2005. Disponível em: <http://jus2.uol.com.br/doutrina/texto.asp?id=6393>. Acesso em: 31 ago. 2005

${ }^{38}$ SGARBOSSA, L. F. A Emenda Constitucional no 45/04 e o novo regime jurídico dos tratados internacionais em matéria de direitos humanos. Jus Navigandi, Teresina, a. 9, n. 575, 2 fev. 


\title{
A RECEPÇÃo de Tratados InTERnACIONAIS SObRe Direitos HuMANOS NO BRASIL APÓS A EMENDA CONSTITUCIONAL N. 45
}

Valério de Oliveira Mazzuoli chama a atenção para alteração no efeito de denúncia dos tratados internacionais, ao dizer o seguinte:

\begin{abstract}
Eles não poderão ser denunciados, nem mesmo com Projeto de Denúncia elaborado pelo Congresso Nacional, podendo ser o Presidente da República responsabilizado em caso de descumprimento a esta regra (o que não é possível fazer tendo os tratados apenas status de norma constitucional). Assim sendo, mesmo que um tratado de direitos humanos preveja expressamente a sua denúncia, esta não poderá ser realizada pelo Presidente da República unilateralmente (como é a prática brasileira atual em matéria de denúncia de tratados internacionais), e nem sequer por meio de Projeto de Denúncia elaborado pelo Congresso Nacional, uma vez que tais tratados equivalem às emendas constitucionais, que são (em matéria de direitos humanos) cláusulas pétreas do texto constitucional. ${ }^{39}$
\end{abstract}

Ou seja, o autor sustenta que os tratados internacionais de proteção de direitos humanos, sejam anteriores ou posteriores à vigência da Emenda 45, gozam de status constitucional. Ele acredita que o quorum previsto no novo parágrafo serviria somente para atribuir efeitos mais amplos a normas que já são materialmente constitucionais. Ou seja, os tratados que respeitassem o procedimento trazido pela Emenda reformariam a Constituição e não poderiam ser denunciados. Entretanto, Mazzuoli acredita que esses efeitos trariam mais prejuízos do que benefícios, ao afastar a idéia de bloco de constitucionalidade material - a qual permite a primazia da norma mais favorável em um confronto de normas. ${ }^{40}$

O autor ainda acrescenta que, diante da referida modificação, atualmente seria necessário verificar se o tratado que se pretende denunciar equivale a uma Emenda Constitucional - material e formalmente constitucional - ou apenas materialmente

2005. Disponível em: <http://jus2.uol.com.br/doutrina/texto.asp?id=6272>. Acesso em: 31 ago. 2005.

${ }^{39}$ MAZZUOLI, V. de O. Reforma do Judiciário e os tratados de direitos humanos. Portal DIEX, Artigos, $30 \quad$ mai. 2005.20 Disponível <http://www.diex.com.br/portal/artigos_det.asp?id=20050530105755564>. Acesso em 5 out. 2005.

${ }^{40}$ MAZZUOLI, V. de O. Integração, eficácia e aplicabilidade dos tratados internacionais sobre direitos humanos no direito brasileiro com especial enfoque para os $\S \S 2^{\circ}$ e $3^{\circ}$ da Constituição Federal de 1988. Exposição apresentada no Painel Regime constitucional de incorporação dos tratados internacionais sobre direitos humanos, em 13 de novembro de 2006, no IX Congresso IberoAmericano e VII Simpósio Nacional de Direito Constitucional, ocorrido no Estação Embratel Convention Center, Curitiba-PR. 
constitucional, em virtude do disposto no $\S 2^{\circ}$ do art. $5^{\circ}$ - mas sem ter passado pelo procedimento indicado pelo $\S 3^{\circ}$. No primeiro caso, a denúncia ensejaria responsabilidade ao denunciante, enquanto no segundo, não.

Percebe-se, portanto, que a solução encontrada por Mazzuoli diante da alteração trazida pela Emenda no que tange à proteção dos direitos humanos - a qual considera "que apenas trouxe imperfeições ao sistema e que certamente prestará um desserviço à interpretação constitucional mais lúcida envolvendo os tratados de direitos humanos dos quais o Brasil é parte" ${ }^{41}$, foi atribuir a ela o papel de divisora dos tratados internacionais sobre direitos humanos em dois grupos diversos: os materialmente constitucionais e os materialmente e formalmente constitucionais. No entanto, ainda que tenha encontrado tal solução, deixa claro que prefere uma nova reforma, que possa trazer uma interpretação autêntica ao $\S 2 .^{\circ}$ do art. $5 .^{\circ}$ da Carta de 1988. Sugere o seguinte texto: "os tratados internacionais referidos pelo parágrafo anterior, uma vez ratificados, incorporam-se automaticamente na ordem interna brasileira com hierarquia constitucional, prevalecendo, no que forem suas disposições mais benéficas ao ser humano, às normas estabelecidas por esta Constituição". ${ }^{42}$

\section{CONSIDERAÇÕES FINAIS}

Primeiramente, foram expostas linhas gerais tanto acerca do que seria um "tratado internacional" - definível como termo genérico do qual fariam partes atos e acordos internacionais praticados por pessoas de Direito internacional público.

Posteriormente, prosseguiu-se a análise da inter-relação entre os Tratados Internacionais de Direitos Humanos e a Constituição da República. Nesta parte,

\footnotetext{
${ }^{41}$ MAZZUOLI, V. de O. Reforma do Judiciário e os tratados de direitos humanos. Portal DIEX, Artigos, 30 mai. 2005.2 Disponível em: $<$ http://www.diex.com.br/portal/artigos_det.asp?id=20050530105755564>. Acesso em 5 out. 2005.

${ }^{42}$ Idem.
} 


\section{A RECEPÇÃo de Tratados INTERNACIONAIS SOBRE DireITOS HUMANOS NO BRASIL APÓS A EMENDA CONSTITUCIONAL N. 45}

mostrou-se a realidade anterior à Emenda Constitucional n. ${ }^{\circ}$ 45, a fim de expor que já se fazia presente a controvérsia acerca do status normativo destes tratados, bem como sobre sua incorporação automática. Percebe-se que a intenção do constituinte de propiciar ao cidadão um sistema mais completo de proteção de seus direitos era sufocada por meio da freqüente interpretação e aplicação conservadora da Constituição.

No ponto central do trabalho, em que se falou sobre a polêmica trazida com a adição do $\S 3^{\circ}$ ao art. $5^{\circ}$, foram expostos diferentes pontos de vista de renomados juristas, a fim de tentar enfocar as possíveis intenções e efeitos do dispositivo referido. A maioria dessas opiniões parece indicar que a modificação legislativa buscou um meio termo entre as diversas opiniões acerca do status normativo das normas de tratados internacionais sobre direitos humanos. Entretanto, essa iniciativa acabou por criar não somente o grave problema da indefinição do status normativo dos tratados assinados pelo Brasil anteriormente à Emenda Constitucional n ${ }^{\circ} 45 / 04$, mas também a possibilidade de engessamento da Carta Magna, ao impossibilitar a prevalência da norma mais favorável pela recepção de normas internacionais que reformariam a Constituição. Os tratados internacionais que passassem pelo procedimento também não poderiam ser denunciados, de tal forma que o desrespeito a suas regras poderia levar à responsabilização do Presidente da República. Ainda que vários estudiosos tenham sugerido respostas a essa dúvida, acredita-se que apenas se chegará a um denominador comum quando essa lacuna for suprida pelo poder constituinte derivado.

Espera-se que o presente ensaio tenha exposto relevantes opiniões doutrinárias acerca desse tema, que traz até hoje muita discussão ao cenário jurídico. Não se teve a pretensão de oferecer uma resposta correta, ou mesmo de apontar determinada perspectiva como a mais adequada, mas sim destacar aspectos pertinentes à questão.

Por derradeiro, vale lembrar da necessidade de que a práxis jurídica comprometa-se com a efetivação do ideário comunitário que se tentou consubstanciar na Constituição, a fim de privilegiar a tutela da pessoa humana - a qual seria a origem e o fim ao qual serve o Sistema Jurídico. Partindo-se dessa premissa, deve-se ter em 
mente que o preciosismo técnico e a visão conservadora da noção de segurança jurídica podem acabar por privilegiar a busca interminável por uma perfeição sistemática, em prejuízo da dignidade humana no caso concreto.

\section{REFERÊNCIAS}

AMARAL JÚNIOR, J. L. M. do. Reforma define o status jurídico de tratados internacionais. Consultor Jurídico. Direitos humanos, 26 de janeiro de 2005. Disponível em: <http://conjur.estadao.com.br/static/text/32678,1>. Acesso em 31 ago 2005.

BALTAZAR, A. H. L. B. Aulas, artigos e entrevistas. 19 de julho de 2005. Disponível em:

$<$ http://www.vemconcursos.com.br/opiniao/index.phtml?page_sub=5\&page_id=1818> . Acesso em 31 ago. 2005

CLÉVE, C. M. Reforma do Judiciário. Palestra proferida em 2 de setembro de 2005, na Universidade Federal do Paraná.

COSTA, A. de C. Reforma gera tumulto em tratados internacionais. Consultor Jurídico. Direitos humanos, 31 de janeiro de 2005. Disponível em: <http://conjur.estadao.com.br/static/text/32678,1>. Acesso em 31 ago 2005.

DUARTE, L. A.. Estudos sobre a posição hierárquica dos decretos legislativos que incorporam tratados. Revista de Direito Constitucional e Internacional, São Paulo, a. 10, n. 41, out./dez 2002.

FERRARI NETO, L. A. Estudo comparado sobre a Emenda Constitucional $\mathrm{n}^{\mathrm{o}}$ 45/2004. Jus Navigandi, Teresina, a. 9, n. 670, 6 maio 2005. Disponível em: <http://jus2.uol.com.br/doutrina/texto.asp?id=6681>. Acesso em: 31 ago. 2005.

FERREIRA, L. A. C.; TÁRREGA, M. C. V. B. Reforma do poder judiciário e direitos humanos. In: WAMBIER, T. A. A. (org.). Reforma do Judiciário: primeiros ensaios críticos sobre a EC n. 45/2004. São Paulo: Revista dos Tribunais, 2005.

HABERMAS, J. Sobre a legitimação pelos direitos humanos. In: MOREIRA, L.; MERLE, J. (Org.). Direito e legitimidade. (Trad. Claudio Molz e Tito Lívio Cruz Romão). São Paulo: Landy, 2003.

JUNQUEIRA, A. L. Implicações da Emenda Constitucional no 45/2004 no Direito Internacional . Jus Navigandi, Teresina, a. 9, n. 614, 14 mar. 2005. Disponível em: 


\section{A RECEPÇÃo de Tratados INTERNACIONAIS SOBRE DireITOS HUMANOS NO BRASIL APÓS A EMENDA CONSTITUCIONAL N. 45}

<http://jus2.uol.com.br/doutrina/texto.asp?id=6393>. Acesso em: 31 ago. 2005

LUCHEZI, R. A Emenda Constitucional no 45 . Jus Navigandi, Teresina, a. 9, n. 560, 18 jan. 2005. Disponível em: <http://jus2.uol.com.br/doutrina/texto.asp?id=6176>. Acesso em: 31 ago. 2005.

MAZZUOLI, V. de O. Reforma do Judiciário e os tratados de direitos humanos. In: Portal DIEX, Artigos, 30 maio 2005. Disponível via WWW. URL: $<$ http://www.diex.com.br/portal/artigos_det.asp?id=20050530105755564>. Acesso em 5 out. 2005.

Integração, eficácia e aplicabilidade dos tratados internacionais sobre direitos humanos no direito brasileiro: com especial enfoque para os $\S \S 2^{\circ}$ e $3^{\circ}$ da Constituição Federal de 1988. Exposição apresentada no Painel "Regime constitucional de incorporação dos tratados internacionais sobre direitos humanos, em 13 de novembro de 2006, no IX Congresso Ibero-Americano e VII Simpósio Nacional de Direito Constitucional, ocorrido no Estação Embratel Convention Center, CuritibaPR.

MORAES, A. de. Direitos humanos fundamentais: teoria geral, comentários aos arts. $1^{\circ}$ a $5^{\circ}$ da Constituição da República Federativa do Brasil, doutrina e jurisprudência. São Paulo: Atlas, 1998.

PASSOS, J. L. T. C. de. Direitos humanos na reforma do judiciário. In: WAMBIER, Teresa Arruda Alvim (org.). Reforma do Judiciário: primeiros ensaios críticos sobre a EC n. 45/2004. São Paulo: Revista dos Tribunais, 2005.

PIOVESAN, F. Direitos humanos e o direito constitucional internacional. Rio de Janeiro: Max Limonad, 2000.

SARLET, I. W. Hierarquia normativa e conflitos de direitos no plano das relações entre tratados e constituição. Exposição apresentada no Painel "Regime constitucional de incorporação dos tratados internacionais sobre direitos humanos, em 13 de novembro de 2006, no IX Congresso Ibero-Americano e VII Simpósio Nacional de Direito Constitucional, ocorrido no Estação Embratel Convention Center, Curitiba-PR.

SGARBOSSA, L. F. A Emenda Constitucional no 45/04 e o novo regime jurídico dos tratados internacionais em matéria de direitos humanos. Jus Navigandi, Teresina, a. 9, n. 575, 2 fev. 2005. Disponível via WWW. URL: <http://jus2.uol.com.br/doutrina/texto.asp?id=6272>. Acesso em: 31 ago. 2005.

SCHIER, P. R. Hierarquia Constitucional dos Tratados Internacionais de Direitos Humanos e EC 45 - tese em favor da incidência do tempus regit actum. Anais do XIV Congresso Nacional do CONPEDI - Conselho Nacional de Pesquisa e PósGraduação em Direito. Fortaleza, de 3-5 de novembro de 2005. Disponível em: $<$ http://www.conpedi.org/manaus/arquivos/Anais/Paulo\%20Ricardo\%20Schier.pdf $>$ A cesso em 29 fev. 2008. 
Revista Eletrônica do CEJUR, Curitiba-PR, a. 2, v. 1, n. 3, ago./dez. 2008

VELlOSO, C. M. da S. Bioética, engenharia genética e direitos humanos: mecanismos constitucionais de proteção dos direitos humanos. Conferência proferida em 12 de novembro de 2006, no IX Congresso Ibero-Americano e VII Simpósio Nacional de Direito Constitucional, ocorrido no Estação Embratel Convention Center, Curitiba-PR. 